\title{
Study on Gastro Intestinal Parasite of Cattle at Horoguduru Animal Production and Research Center of Wollega University, Oromia, Ethiopia
}

\author{
Belay Beyene*
}

Department of Animal Science, Faculty of Agriculture, Wollega University, Shambu Campus, P.O. Box: 38, Shambu, Ethiopia

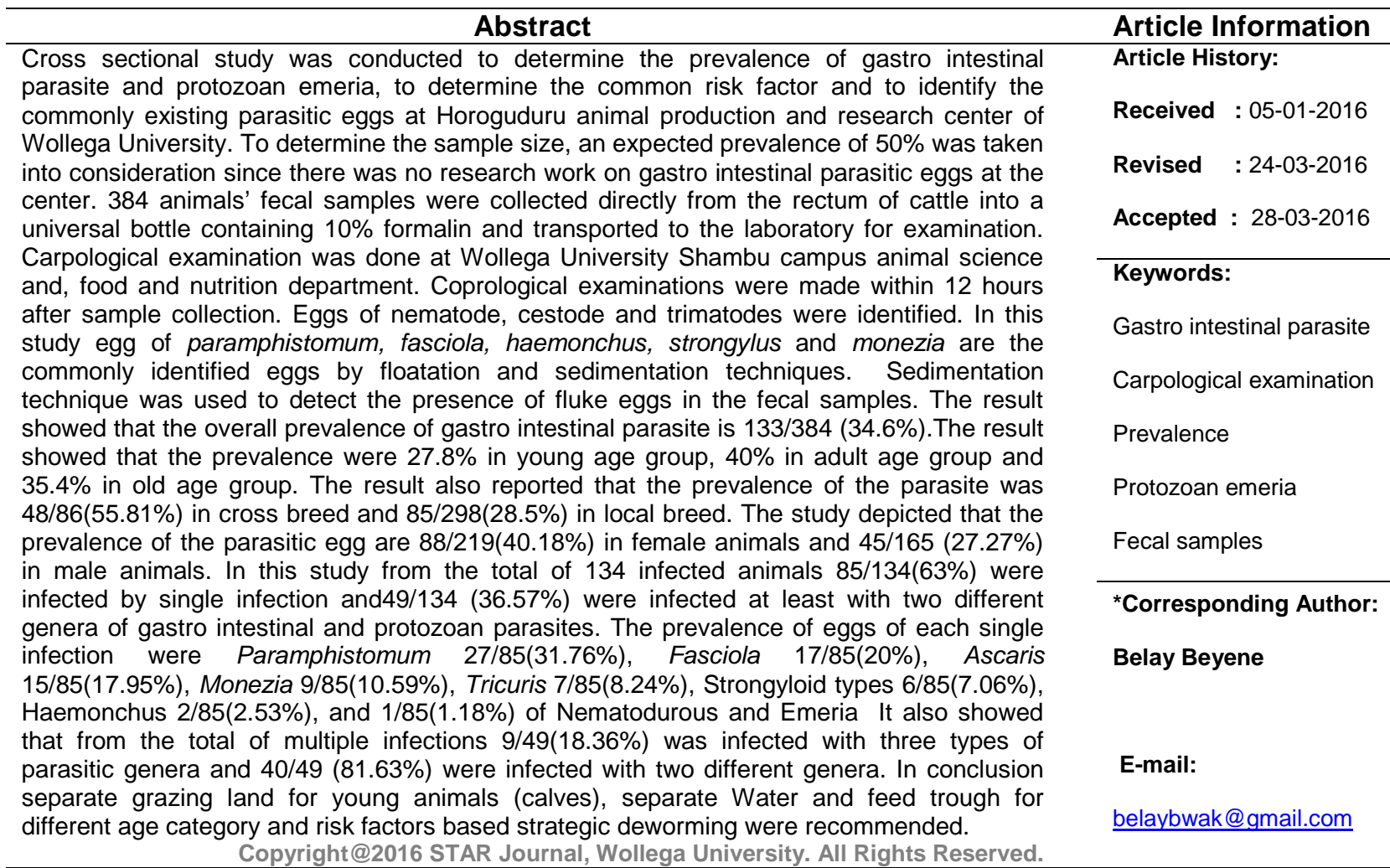

\section{INTRODUCTION}

Gastrointestinal helminthes infections are recognized as a major constraint to livestock production throughout the tropics and elsewhere. They cause lowered productivity, cause mortality, and high economic losses affecting the income of small holder dairy farming communities (Ferede, 2013). Cattle of all ages become infected with many species of parasites. However, clinical disease caused by parasitism is mainly observed in groups of animals under 18 months of age. The severity and prevalence of the young animal are series when the availability of large numbers of the infective stages of the parasite and when the susceptible cattle graze on contaminated area. In such situation, large numbers of parasites develops in a specific host organ and produces severe tissue disruption as a consequent signs of parasitism (Andrews et al., 2004).
Gastro Intestinal parasite is known by causing parasitic gastroenteritis (PGE). In livestock the common cause are included under the genera nematode such as Trichostrongylus, Ostertagia, Cooperia, and Nematodirus and Oesophagostomum and the hookworms. They are commonly occur in the alimentary tract of ruminants (Radostits et al., 2008). The term PGE is associated with the presence of large numbers of nematodes in the abomasums and intestines rather than any other endoparasites (Andrews et al., 2004). The nematodes are commonly called roundworms, from their appearance in crosssection. The phylum Nemathelminthes has six classes. However, only one of these, the nematoda, contains worms of parasitic significance (Urquhart et al., 1996). The main aim of Animal production and research center of Wollega University are for genetic conservation 
Belay Beyene

of Horo cattle breed and nucleus breeding of horo breeds; besides it produce cross breed of Horo cattle and distribute $\mathrm{F} 1$ cross to the community.

Even though, the case report in the veterinary clinic and tentative diagnosis indicated the presence of the endo parasite; there is no study done on its prevalence and risk factors. Therefore, objectives of this study were to determine the prevalence of the Parasite and to determine the common risk factors.

\section{MATERIALS AND METHODS}

\section{Study Area}

Ethiopia has from Federal to Peasant association administrative structure, as Federal government is the collection of region, region has a power to govern each zones under its geographic and ethnic control. Horoguduru Wollega zone is located in the Western part of oromia region. It is bounded by west Showa zone, East wollega and partly by Jimma zone. Farmers in Horoguduru Wollega zone of oromia region lead their lively hoods by live stock keeping and crop production. In this study cattle of Horo Guduru Animal Production and Research Center of Wollega University which is located in Guduru District of Horo Guduru Wollega Zone are the target group.

\section{Study Population}

Cattles in Horoguduru Animal Production and Research Center of Wollega University were considered as study animal.

\section{Sampling methods and sample size determination}

Live animal examination was conducted on fecal samples collected directly from the rectum of cattle into a universal bottle containing 10\% formalin and transported to the laboratory for examination. Sampling was carried out at random with inclusion of age, sex, breed, and body condition of animals. To determine the sample size, an expected prevalence of $50 \%$ was taken into consideration since there was no research work on gastro intestinal parasitic eggs of the center. The desired sample size for the study was calculated using the formula given by Thursfield (2005) with 95\% confidence interval and 5\% absolute precision.

Therefore,

$\mathrm{TS}=\frac{(1.96)^{2} * \operatorname{Pexp}(1-\text { Pexp })}{\mathrm{d}^{2}}$

TS $=\frac{(3.8416)(0.5 * 0.5)}{0.0025}=384($ Thrusfield, 2007);

Where,

Pexp= expected prevalence $=50 \%$

$\mathrm{d}=$ desired absolute precision $=0.05$ at $95 \% \mathrm{Cl}$

Ts $=$ total number of animals sampled

\section{Data and Sample Collection Questionnaire}

Questionnaire was developed at Wollega University Shambu Campus and was administered to herderman by the researcher and workers of the center. Since the animals are under the same management system there was no risk factor assessment at management related or herd level factor. Animal level questionnaires were collected from the retrospective data and direct interview of herderman. Animal level questionnaire includes the individual details such as animal Id, Sex, Age and Breeds;
Sci. Technol. Arts Res. J., Jan-March 2016, 5(1): 46-50

treatment with antihelmentic drug within the last three month. if yes types of drug.

\section{Fecal Sample Collection and Examination}

Fecal samples were collected from each animal in different test tubes. Using a plastic glove, five grams of fresh fecal matter pr animal was collected from the rectum or during defecation.

Samples was stored in plastic bags, well labeled, and placed in icebox until used. The test tube was coded for each sample. Sample was examined at the center's Animal health clinic. Coprological examinations were made within 12 hours after sample collection. Eggs of nematode, cestode and trimatodes were identified at Shambu campus Animal science and, food Science and Nutrition laboratory. In this study egg of paramphistomum, fasciola, haemonchus, strongylus and monezia are the commonly identified eggs by floatation and sedimentation techniques. Sedimentation technique was used to detect the presence or absence of fluke eggs in the fecal sample collected. To differentiate between eggs of paramphistomum species and fasciola species, a drop of methylene blue solution was added to the sediment.

\section{Data Management and Analysis}

Collected data was entered into MS Excel spreadsheet (Excel, 2007). Descriptive statistics and percentage were analyzed in Excel spread sheet and SPSS software. Total prevalence was calculated as the number of coprological positive sample divided into total tested animals. Prevalence for different species of parasite was analyzed separately as the number of positive animals to total number of tested animal. Chi-square test, odds ratio and univariable logistic regression model were used. Chisquare was used to identify the level of significance between dependant and independent factor. The risk factors that favors occurrence of endo parasite for all species of test positive and that separately favors each species were considered as independent variable while coprological positive was considered as dependant factor.

In all cases, the 95\% confidence interval and the 5\% level of significances was used to declare the significant difference.

\section{RESULTS}

In this study a total of 384 samples were collected from the total cattle population in Horoguduru Animal production and research center of Wollega University, Guduru. All animals were under the same management system. The retrospective data analysis showed that there were no scheduled deworming and no animals were dewormed for the last three months.

Breed age, sex and parity were considered as the main contributing factors. The external factor $s$ like grazing type, housing, macro and micro climate were the same for all cattle of the study groups because the animals are living in the same center and under the same management system. The result showed that the overall prevalence of gastro intestinal parasite is 134/384 (34.6\%). The study showed that the prevalence were $27.8 \%$ in young age group, $40 \%$ in adult age group and $35.4 \%$ in old age group. The prevalence of the disease is higher in adult and old age group than young age group. The result also reported that the prevalence of the disease is $48 / 86(55.81 \%)$ in cross breed and 


\section{Belay Beyene}

$85 / 298(28.5 \%)$ in local breed. Analysis of the data showed that the prevalence of the parasite is statistically highly significant in cross breed animals than the local breed. The study depicted that the prevalence of the parasitic egg are 88/219(40.18\%) in female animals and 45/165 $(27.27 \%)$ in male animals (Table 1$)$.

In this study the effect of parity is statistically significant in the prevalence of parasitic eggs. The eggs count decreases as age of the animals increases.
Sci. Technol. Arts Res. J., Jan-March 2016, 5(1): 46-50

Prevalence of the egg count in parity of $\leq 2,2-\leq 4$ and $>4$ are $43.2 \%, 31.8 \%$ and $30 \%$ respectively (Table 2 ).

In the univariable logistic regression both sex and breed are statistically significant. The result showed that females are 1.78 times at risk than male. Breed is the main contributing risk factors for the release of parasitic egg. It showed that cross breed is likely 3.15 times at risk than the local breed (Table 3)

Table 1: Risk factor Analysis of Gastro intestinal parasite at Horo Guduru animal production and research Center

\begin{tabular}{lccccc}
\hline Parameter & Number Tested & Positive & Prevalence (\%) & c2 & P-Value \\
\hline Breed & & & & & \\
Cross & 86 & 48 & 55.81 & & 0.0001 \\
Horo & 298 & 85 & 28.5 & & \\
\hline Sex & & & & & \\
Female & 219 & 88 & 40.18 & 6.9 & 0.008 \\
$\quad$ Male & 165 & 45 & 27.27 & & \\
\hline Age & & & & & \\
Young & 126 & 35 & 27.8 & & \multirow{2}{*}{0.1} \\
Adult & 145 & 58 & 40 & 4.1 & \\
$\quad$ Old & 113 & 40 & 35.4 & & \\
\hline Total & $\mathbf{3 8 4}$ & $\mathbf{1 3 3}$ & $\mathbf{3 4 . 6 3}$ & &
\end{tabular}

Table 2. Effect of parity on prevalence of Gastro Intestinal parasite at Horoguduru animal production and research center

\begin{tabular}{cccccc}
\hline Parameter & No. tested & Positive (\%) & Prevalence & c2 & P-Value \\
\hline No of Parity & & & & & \\
$\leq 2$ & 162 & 70 & 43.2 & & \\
$2-\leq 4$ & 44 & 14 & 31.8 & 25 & 0.001 \\
$>4$ & 13 & 4 & 30.8 & & \\
\hline
\end{tabular}

Table 3: Univariable Logistic regression

\begin{tabular}{lllll}
\hline Parameter & S.E & Wald & Sig & Exp(B) \\
\hline Sex & 0.022 & 6.65 & 0.01 & 1.776 \\
Breed & 0.25 & 20.69 & 0.0001 & 3.15 \\
\hline
\end{tabular}

In this study from the total of 134 infected animals $85 / 134(63 \%)$ were infected by single infection. The eggs of nine different genera were identified (namely: paramphistomum, fasciola, Asraris, Monezia, tricuris, Strongyloid types of egg, Haemonchus, Nematodurous and Emeria).
The prevalence of eggs of each single infection were Paramphistomum 27/85(31.76\%), Fasciola 17/85(20\%), Ascaris 15/85(17.95\%), Monezia 9/85 (10.59\%), Tricuris 7/85(8.24\%), Strongyloid types 6/85(7.06\%), Haemonchus 2/85(2.53\%), and 1/85(1.18\%) of Nematodurous and Emeria (Table 4).

Table 4: Single infection of helminthes and emeria parasite at horoguduru animal production and research center

\begin{tabular}{lcc}
\hline \multicolumn{1}{c}{ Types of Parasite } & No of animals infected & Prevalence (\%) \\
\hline Paramphistomum & 27 & 31.76 \\
Fasciola & 17 & 20.00 \\
Ascaris & 15 & 17.65 \\
Monezia & 9 & 10.59 \\
Tricuris & 7 & 8.24 \\
Strongyloid types of egg & 6 & 7.06 \\
Haemonchus & 2 & 2.35 \\
Nematodurous & 1 & 1.18 \\
Emeria & 1 & 1.18 \\
\hline \multicolumn{2}{c}{ Total } & $\mathbf{8 5}$ \\
\hline \multicolumn{2}{c}{}
\end{tabular}

Table $\mathrm{V}$ showed that from the total of 134 animals positive to the parasitic egg 49/134 (36.57\%) were infected at least with two different genera of gastro intestinal and protozoan parasites. The study revealed that from the total of multiple infections $9 / 49(18.36 \%)$ was infected with three types of parasitic genera. The data also showed that $40 / 49(81.63 \%)$ were infected with two different genera. It depicted that there were sixteen (16) types of multiple infection (table 5). 
Table 5: Multiple infection of Gastro intestinal and protozoan parasites in Horoguduru Animal production and research center

\begin{tabular}{|c|c|c|}
\hline Types of the Parasitic Eggs & $\begin{array}{c}\text { No of Animals } \\
\text { Infected }\end{array}$ & Prevalence (\%) \\
\hline Paramphistomum and monezia & 4 & 8.16 \\
\hline Fasciola, paramphistomum, Haemoncus & 5 & 10.20 \\
\hline Ascaris, fasciola and paramphistomum & 1 & 2.04 \\
\hline Fasciola and paramphistomum & 12 & 24.49 \\
\hline Haemoncus and paramphistomum & 1 & 2.04 \\
\hline Fasciola and Ascaris & 4 & 4.08 \\
\hline Fasciola and monezia & 1 & 2.04 \\
\hline Ascaris and paramphistomum & 4 & 8.16 \\
\hline Ascaris and Haemonchus & 3 & 4.08 \\
\hline Paramphistomum and Emeria & 1 & 2.04 \\
\hline Ascaris, Paramphistomum and emeria & 1 & 2.04 \\
\hline Nematodureous and Emeria & 2 & 4.08 \\
\hline Fasciola and Nematodurius & 3 & 6.12 \\
\hline Strongyloid and monezia & 1 & 2.04 \\
\hline Ascaris and strongloid & 3 & 6.12 \\
\hline Ascaris and Nematodurius & 1 & 2.04 \\
\hline Haemoncus and strongloid & 2 & 4.08 \\
\hline Fasciola, Strongloids, Monezia & 2 & 4.08 \\
\hline Total & 49 & 36.57 \\
\hline
\end{tabular}

\section{DISCUSSION}

In this study the overall prevalence of $34.63 \%$ was slightly similar with the finding $27.57 \%$ of Awraris et al. (2012) reported from Cattle in and Around Gondar Town. The prevalence of current finding is lower than the report of (Telila et al., 2014) that conducted study at Central Ethiopia and indicated the total prevalence of gastrointestinal helminthes egg $61 \%$. The difference of prevalence in same country is related to the management system, macro and microclimatic condition. Kumsa et al. (2011) reported prevalence of helminthes in small ruminant in Central Ethiopia was $81.5 \%$. Similarly Shankute et al. (2013) reported the prevalence of the helminthes parasite were $86.93 \%$ and $86.48 \%$ in sheep and goats in central Ethiopia. Both finding were higher than the current result. The significant difference of prevalence in the current result of cattle and previous report of small ruminant is mainly due to the grazing behavior of the animals.

The high prevalence of the parasitic egg in female than male was previously reported by Ferede (2013) from Ethiopia. The current finding is in agreement with Ferede (2013) finding. The justification why the parasitic eggs prevalence were higher in female than male is related the biological activity of the animals. Females' immunity is depressed during pregnancy and lactation in comparison to male. In the current study the prevalence of parasitic egg was $55.81 \%$ in cross breed and $28.5 \%$ in local or Horo breed. The statistically significant difference between cross and local breed was previously reported by (Ferede, 2013). The reason why the prevalence of the disease is high in cross breed than local breed is because cross breed were highly productive and susceptible to disease. the finding of single infection 85/134(63.43\%) prevalence of different genera were in agreement with the finding of Bacha and Haftu, (2015) who reported of the total $49 \%$ positive sample $57.97 \%$ were infested with single genera of gastrointestinal. In the current finding the single infection $85 / 134(63.43 \%)$ of the prevalence of different genera were Paramphistomum 27/85(31.76\%), Fasciola 17/85(20\%), Ascaris 15/85(17.95\%), Monezia 9/85 (10.59\%), Tricuris 7/85(8.24\%), Strongyloid types
6/85(7.06\%), Haemonchus 2/85(2.53\%), and 1/85(1.18\%) of Nematodurous and Emeria.This finding of different parasitic eggs in the same farm were previously reported by Awraris et al. (2012) who reported 57\% Ascaris, $56.07 \%$ Strongyle-type and $16.82 \%$ Trichuris spp. Similarly, study conducted at Central Ethiopia indicated the total prevalence of gastrointestinal helminthes egg was $61 \%$ with respect to their genera were Strongyle $41 \%$, Fasciola $36.5 \%$, Paraphostomum 18.4\%, Toxocara 7.7\%, Trichuris 5.2\%, and Monezia 2.8\% (Telila et al., 2014). Bacha and Haftu, 2015 reported the commonly identified egg belongs to ostertagia spp.1.8\%, oesophagostomum spp. 1.3\%, strongloid spp. 2.6\%, Emeria spp. 2.9\%, Trychostrongylus spp.3.6\%, hemonchus spp. $11.7 \%$, Bunostomum spp. $4.4 \%$ and the rest $42.02 \%$ animals were infested with mixed genera of gastro intestinal nematodes.

\section{CONCLUSIONS}

The fecal samples were collected from the total of 384 animals from Horoguduru animal production and research center and examined at wollega University Shambu Campus animal science and, food science and nutrition department. The studies revealed that from the total tested faces $134 / 384(34.41 \%)$ were positive to at least one economically important parasitic egg.

The study showed that breed, age and parity were the main risk factors for the occurrence of the disease. Even though there is veterinary clinic for the treatment of diseased animals; there was no strategic deworming of the parasite in the farm. There were also no separate grazing area for young animals (calve). The water trough of adult and calves were same. The $34.41 \%$ of prevalence indicated that large proportions of animals were infected with the parasite.

The results of the study recommends that, there should be separate grazing land for young animals (calves), water and feed trough should be different for age category and there should be risk factors based strategic deworming. 


\section{Belay Beyene}

\section{Acknowledgments}

The author is greatly thankful to Wollega University for providing financial support. The author appreciates the support and understanding of workers' of Horguduru animal production and research center of Wollega University. My gratitude also extends to animal Science and Food Science and Nutrition Department Laboratory Technicians'.

\section{Conflicts of Interest}

The author declares that he has no conflict of interest.

\section{REFERENCES}

Andrews, A.H., Blowey, R.W., Boyd, H. and Eddy, R.G. (2004). Bovine Medicine Diseases and Husbandry of Cattle; $2^{\text {nd }}$ edition, Blackwell Science publisher, UK.

Awraris, T., Bogale, B. and Chanie, M. (2012). Occurrence of Gastro Intestinal Nematodes of Cattle in and Around Gondar Town, Amhara Regional State, Ethiopia. Acta Parasitologica Globalis 3(2): 28-33.

Bacha, A. and Haftu, B. (2015). Study on Prevalence of Gastrointestinal Nematodes and Coccidian Parasites Affecting Cattle in West Arsi zone, Ormia Regional State, Ethiopia. Global Journal of Animal Scientific Research 3(1): 77-86.

Ferede, Y. (2013). Epidemiology of gastrointestinal Helminthiasis of crossbred calves In selected sites of
Sci. Technol. Arts Res. J., Jan-March 2016, 5(1): 46-50

bahir dar zuria And gozamen districts of amhara region, Northwest Ethiopia. International Journal of Pharma Medicine and Biological Science 2(3): 18-27.

Kuma, B., Tadesse,T., Sori,T., Duguma R. and Hussen,B. (2011). Helminths of Sheep and Goat in Centeral Oromia (Ethiopia) During the dry season. Journal of Animal and Veterinary Advance10(14): 1845-1849.

Polley, L. (2010). Veterinary Science, Veterinary Helminthology. Western college of Veterinary Medicine, University of Saskatchewan, Saskatoon, Canada.

Radostits, O.M., Blood, D.C. and Gay, C.C. (2008). Veterinary Medicine, $9^{\text {th }}$ ed., W.B. Saunders Co., Philadelphia.

Shankute, G., Bogale, B. and Melaku, A. (2013). An Abattoir Survey on Gastrointestinal Nematodes in Sheep and Goats in Hemex- Export Abattoir, Debre Ziet, Central Ethiopia. Journal of Advanced Veterinary Research 3: 6063.

Telila, C.H., Abera, B., Lemma, D. and Eticha, E. (2014). Prevalence of gastrointestinal parasitism of cattle in East Showa Zone, Oromia Regional State, Central Ethiopia. Journal of Veterinary Medicine and Animal Health 6(2): 54-62.

Urquhart, G.M., Armour, J., Duncan, J.L., Dunn, A.M. and Jennings, F.W. (1996). Veterinary Parasitology. $2^{\text {nd }}$ Edition, Blackwell, Science Scotland. 